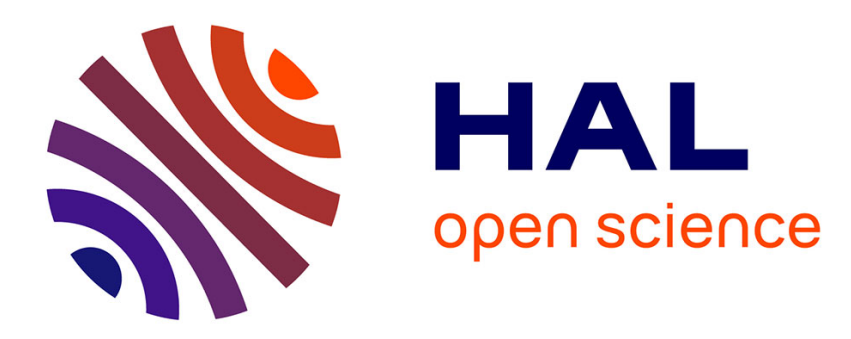

\title{
Multiphoton transitions in gases at microwave frequencies
}

\author{
G. Alzetta, A. Battaglia
}

\section{To cite this version:}

G. Alzetta, A. Battaglia. Multiphoton transitions in gases at microwave frequencies. Journal de Physique Lettres, 1983, 44 (18), pp.755-759. 10.1051/jphyslet:019830044018075500 . jpa-00232259

\section{HAL Id: jpa-00232259 https://hal.science/jpa-00232259}

Submitted on 1 Jan 1983

HAL is a multi-disciplinary open access archive for the deposit and dissemination of scientific research documents, whether they are published or not. The documents may come from teaching and research institutions in France or abroad, or from public or private research centers.
L'archive ouverte pluridisciplinaire HAL, est destinée au dépôt et à la diffusion de documents scientifiques de niveau recherche, publiés ou non, émanant des établissements d'enseignement et de recherche français ou étrangers, des laboratoires publics ou privés. 
Classification

Physics Abstracts

$33.20 \mathrm{~B}-33.80 \mathrm{~K}$

\title{
Multiphoton transitions in gases at microwave frequencies
}

\author{
G. Alzetta and A. Battaglia \\ Dipartimento di Fisica dell'Universitá Pisa, Italy
}

(Reçu le 13 juin 1983, révisé le 22 juillet, accepté le 28 juillet 1983)

\begin{abstract}
Résumé. - Nous avons engendré des transitions à plusieurs photons en irradiant un gaz avec deux sources de radiation microonde. On a ainsi étudié des transitions à trois photons dans l'ammoniac et le sulphure de carbonyle en fonction de la fréquence, de la puissance rayonnée et de la densité des gaz. Nos résultats sont en assez bon accord avec les prédictions théoriques.
\end{abstract}

\begin{abstract}
Multiphoton transitions are produced irradiating a gas by two microwave power sources. Three-photon transitions in $\mathrm{NH}_{3}$ and OCS have been studied in function of frequencies, power and density of gases. Measurements agree fairly well with theoretical predictions.
\end{abstract}

Three-photon transitions in the optical region have been observed and related by some authors [1].

We describe a similar experiment that has been realized in the region of microwaves at centimetre wavelength in gases at few $\mu \mathrm{Hg}$ of pressure.

The gas in a waveguide cell was irradiated by two strong waves at frequencies $v_{1}$ and $v_{2}$, both very close either to the resonance frequency $v_{0}$ of the $(3,3)$ absorption line of inversion spectrum of $\mathrm{NH}_{3}$ or to that of the line $J=1 \rightarrow 2$ of pure rotational spectrum of carbonyl sulfide OCS. The frequency $v_{1}$ is fixed at a distance $\Delta v$ from $v_{0}$, the second wave is swept in frequency between $v_{0}$ and $v_{1}$. The frequency interval $\Delta v$ is several linewidth wide, and $v_{1}<$ or $>v_{0}$.

A schematic mechanism of three-photon transitions is shown in figure $1 a$ and $b$. In the case $v_{1}<v_{0}$ (Fig. 1 $a$ ), the virtual levels are traced at a distance $\Delta v$ from real levels connected by the transition at $v_{0}$ frequency. The process occurs when

$$
2 v_{1}-v_{2}^{\prime}=v_{0} \text {. }
$$

Two photons are absorbed from the wave $v_{1}$ and one is emitted at the frequency $v_{2}^{\prime}$. In the second case (Fig. $1 b$ ) the process is the same but the virtual levels are outside the real ones. The absorption and emission coefficients $\gamma_{1}$ and $\gamma_{2}$ have been calculated by means of the complex operator of Liouville [2]. The expansion parameters are of the kind

$$
\left|E \mu /\left(\omega_{0}-\omega_{1}\right)\right|
$$

which are supposed to be $<1$, and in the hypotesis

$$
\left|2 \omega_{1}-\omega_{2}-\omega_{0}\right| \ll\left|\omega_{1}-\omega_{0}\right|
$$




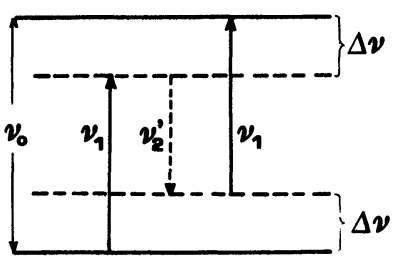

a)

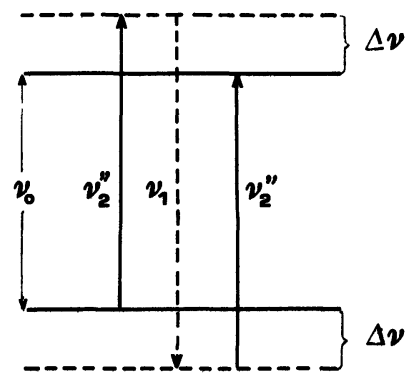

b)

Fig. 1a,b. - Energy level diagram : schematic of three-photon transition.

we have for the first case :

$$
\begin{aligned}
& \gamma_{1}=-\frac{8 \pi}{C E_{1}^{2}} \omega_{1} N F^{2} \frac{1 / T_{2}}{\left(\omega_{\mathrm{r}}-\omega_{0}+S\right)^{2}+2 F^{2} \frac{T_{1}}{T_{2}}+\frac{1}{T_{2}^{2}}} \frac{\omega_{0}-\omega_{2}}{\omega_{0}-\omega_{1}} \\
& \gamma_{2}=\frac{8 \pi}{C E_{2}^{2}} \omega_{2} N F^{2} \frac{1 / T_{2}}{\left(\omega_{\mathrm{r}}-\omega_{0}+S\right)^{2}+2 F^{2} \frac{T_{1}}{T_{2}}+\frac{1}{T_{2}^{2}}} \\
& F=\mu^{3} \frac{E_{1}^{2} E_{2}}{\left(\omega_{0}-\omega_{1}\right)\left(\omega_{1}-\omega_{2}\right)} ; \quad S=-\mu^{2} \frac{2 E_{1}^{2}+E_{2}^{2}}{\omega_{1}-\omega_{2}}
\end{aligned}
$$

with

$T_{1} \quad$ : longitudinal relaxation time,

$T_{2}$ : transversal relaxation time (for ammonia we assume $T_{1} \cong T_{2}$ ),

$E_{1}, E_{2}$ : electric fields of $v_{1}$ and $v_{2}$ waves,

$\mu \quad$ : electric dipole moment of transition,

$N \quad$ : molecular density,

$S \quad$ : radiation shift,

and where $\omega_{\mathrm{r}}=2 \omega_{1}-\omega_{2}$.

With appropriate approximations it is possible to deduce for the multiphoton an absorption of power of the kind [3] :

$$
\Delta P=P_{1} P_{2}^{2}
$$

and

$$
\Delta P=\left(\omega_{0}-\omega_{1}\right)^{-4}
$$

and a dependence from the pressure equal to that of the one-photon line.

Figure 2 schematizes the spectrometer that we have set up to work in the K-band $(24 \mathrm{GHz})$.

Two klystrons $K_{1}$ and $K_{2}$ are used as microwave generators (EM 1188) with $1 \mathrm{~W}$ of maximum power output. $K_{1}$ is stabilized in frequency through a tunable cavity $C_{1}$ with a very small frequency modulation at $5 \mathrm{kHz}$. The wave $v_{2}$ is frequency modulated with the sawtooth of the oscilloscope. The waves $v_{1}$ and $v_{2}$ feed a Stark absorption cell, $50 \mathrm{~cm}$ length, through two decoupled arms of a magic $T$. The power of the two waves in the cell can be controlled and measured by means of two 


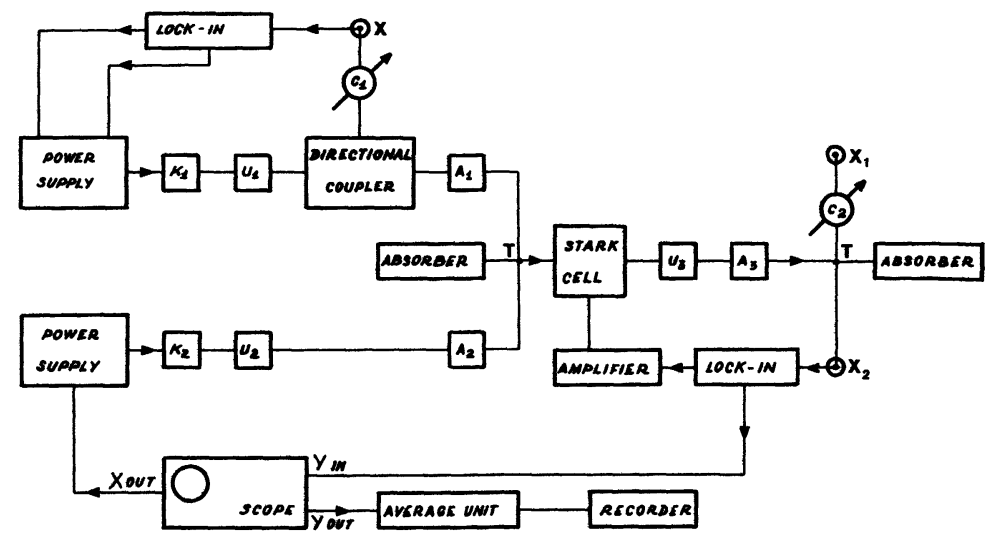

Fig. 2. - Diagram of Stark spectrometer.

calibrated absorbers $A_{1}$ and $A_{2}$. The signals are detected by the crystal $X_{2}$ in one of the $H$ arms of a magic $\mathrm{T}$, or by the crystal $\mathrm{X}_{1}$ in the other $\mathrm{H}$ arm ; in this case the signal is filtered by a tunable cavity $\mathrm{C}_{2}$.

These crystals are protected and insulated by means of a calibrated absorber $\mathrm{A}_{3}$ and an uniline $U_{3}$. The low-frequency signals are amplified by a lock-in and monitored on a scope.

The signals are optimized, when necessary, with the time-averaging technique and successively recorded. Since the two photons absorbed and the one emitted are of different frequency, the observation in $\mathrm{X}_{2}$ evidences a net absorption while the detection in $\mathrm{X}_{1}$ with the opportune tuning to $v_{1}$ or $v_{2}$ frequency of the cavity $\mathrm{C}_{2}$ reveals the emission or the absorption (Fig. 3 ).

With $A_{1}$ and $A_{2}$ completely open (maximum power in the cell) a signal is detected in $X_{2}$ showing transitions at 1, 3 and 5 photons (Fig. 4).

The intensities of the three-photon transitions have been measured as a function of the power $P_{1}$ and $P_{2}$. These measurements agree fairly well with (1) since it has been found a proportionality to

$$
P_{1}^{0.96} \cdot P_{2}^{2.06}
$$

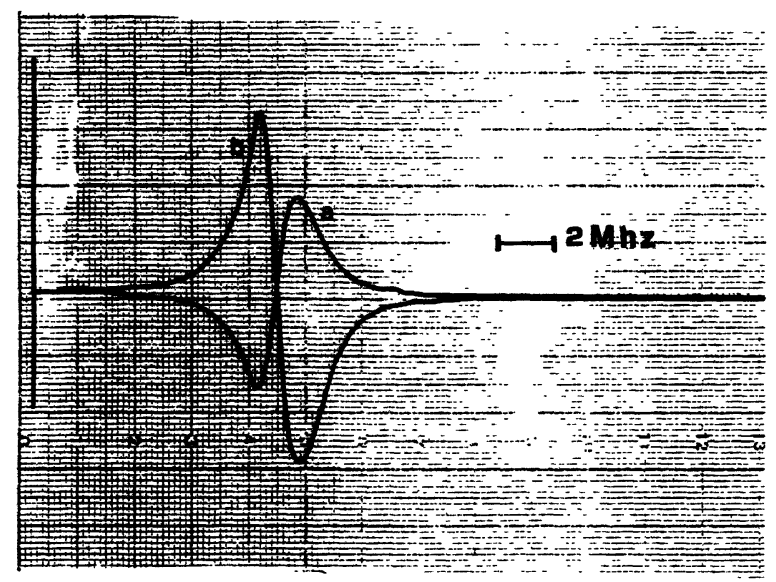

Fig. 3. - Emission (a) observed with the cavity $\mathrm{C}_{2}$ tuned to the frequency $v_{2}^{\prime}$, and absorption $(b)$ with the same cavity tuned to $v_{1}$ i.e. the spectrometer is operating in the conditions reported in figure $1 a$. 


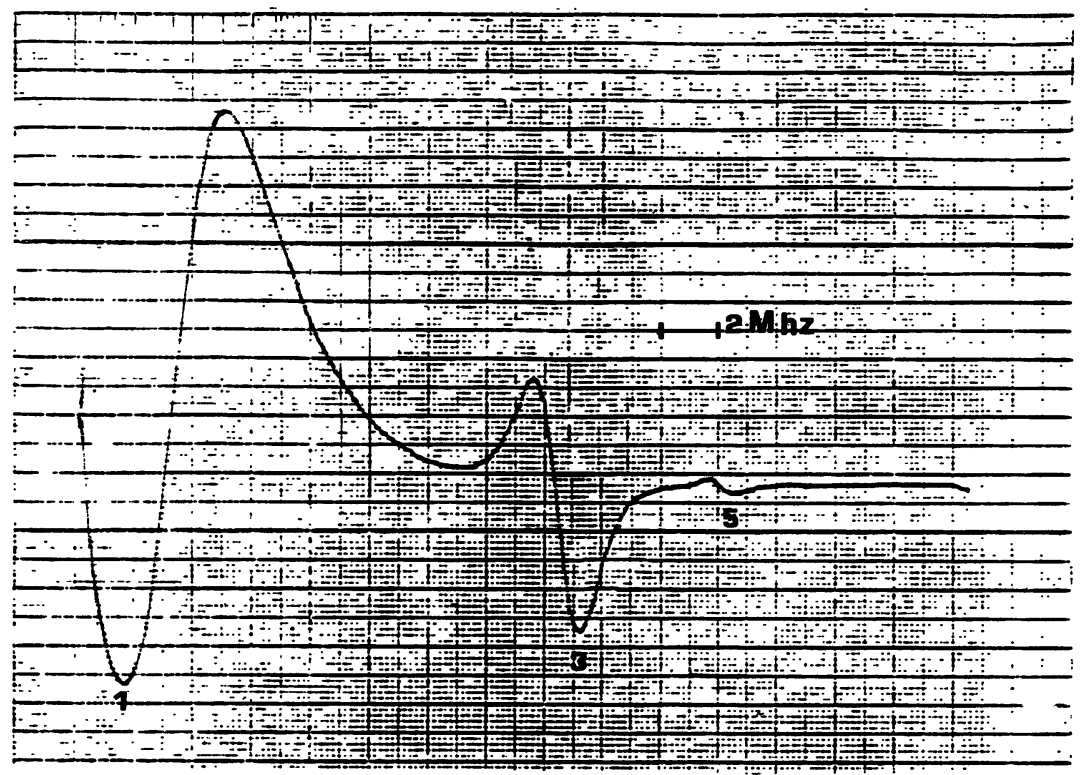

Fig. 4. - A typical diagram showing absorption of one, three and five photons in $\mathrm{NH}_{3}$.

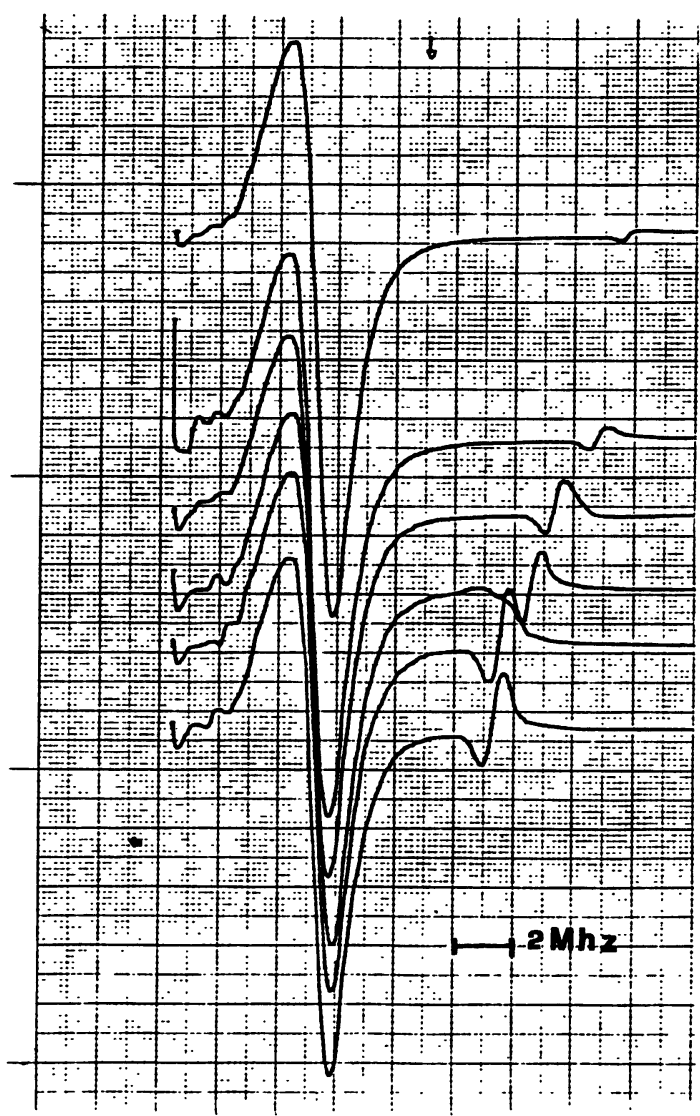

Fig. 5. - Three-photon line intensity as a function of the distance from the main $(3,3) \mathrm{NH}_{3}$ absorption line. 
At several values of $P_{1}$ and $P_{2}$ the intensity of three-photon line was measured point by point as a function of the frequency $v_{1}$, that is

$$
\Delta v=v_{0}-v_{1}
$$

and it was found a dependence of the kind

$$
\Delta P=\Delta v^{-4.2}
$$

instead of a fourth-power behaviour (Fig. 5). The measurement reveals a dependence from the pressure of the linewidth which is the same and has the same value as that of the one-photon line.

In ammonia the effect is much stronger than in carbonyl sulphide and the measurements easier, but a good source of errors in the case of $\mathrm{NH}_{3}$ is the instability of the pressure in the cell.

It is worthwhile to underline that amplification of a wave takes place, so that a tunable MASER can be conceived to work in the nearness of a microwave absorption line.

\section{Acknowledgments.}

We wish to acknowledge the assistance of F. Sbrana and G. Villa for their help in performing the experiments.

\section{References}

[1] Grynberg, G., Biraben, F., Bassini, M., Cagnac, B., Phys. Rev. Lett. 37 (1976) 283;

Steardo, P. C., Tesi di Laurea, Universita di Pisa (1977).

[2] Di Giacomo, A., Santucci, S., Nuovo Cimento 63B (1969) 407 ;

FANO, U., Rev. Mod. Phys. 29 (1957) 74 ;

Zwanzig, R., Lectures in Theoretical Physics, ed. E. Brittin, vol. 3 (New York, N.Y.) 1961.

Di Giacomo, A., Feo, F., Nuovo Cimento 25B (1975) 730.

[3] Brossel, G., Quantum Optics and Electronics (Gordon \& Breach) 1964, p. 287. 